\title{
Polyether ether ketone (PEEK) and its 3D printed implants applications in medical field: An overview
}

\author{
Abid Haleem, Mohd Javaid* \\ Department of Mechanical Engineering, Jamia Millia Islamia, New Delhi, India
}

\section{A R T I C L E I N F O}

\section{Keywords:}

3D printing

Additive manufacturing (AM)

Applications in medical

Implants

Medical

PEEK

\begin{abstract}
A B S T R A C T
Background: Extensively studied research articles on Polyether ether ketone (PEEK) in "medical" and "PEEK 3D printing in the medical field" to identify a direction of the development and identify critical applications in medicine.

Materials and methods: This is a literature-based study of research articles listed in Scopus. A literature review \& bibliometric analysis is done to achieve the research objective.

Results: Searching keywords as "PEEK" "medical" through Scopus identified 426 research articles and searching "PEEK" "medical" "3D printing" identified ten articles. This study identifies that PEEK is a suitable material that helps innovation and helps to solve different surgical and medical problems. Analysis of the Scopus data depicts an increasing trend in the medical field, especially the application of this material. Much research is done on PEEK in medical, but there is very less work reported on PEEK 3D printing in medical. 3D PEEK implants are preferred in medical for requirements of extensive customisation. This technology caters well to the manufacturing of prosthetics, artificial bone, heart \& its parts and other human parts. Finally, twelve important applications areas are identified in medical.

Conclusion: PEEK has somewhat bone like properties. This material can be well used in 3D printing technologies to help fulfil various challenges of the medical. In medical, PEEK materials foresee different surgical application as it can replace titanium and ceramic implants. The need is to explore the use of PEEK in different surgeries of orthopaedic, spine, maxilla-facial, cranial and others 3D printing manufactures complex design implants as per requirement of a patient with an exact match. This material is also applicable for cardiac surgery like manufacturing of heart valve prostheses and leaflet heart valves. PEEK material is hard, lightweight, stiff and is a robust polymer while having satisfactory wear properties that help implants with an extended life. In dentistry, PEEK implants have also the potential for use in tooth replacement. It seems somewhat cost-effective to fulfil innovative medical requirements with comparable wear and mechanical strength.
\end{abstract}

\section{Introduction}

Polyether ether ketone (PEEK) is a thermoplastic organic polymer, that is becoming increasingly popular due to its applications for the manufacturing of medical tools, devices, implants and associated types of equipment. PEEK, was developed by US aerospace industry in the late 1970s. Its medical usage started in the 1980s and followed in 1990s for clinical studies and manufacturing of implants and has properties of stability at high temperature. ${ }^{1,2}$

Nowadays, a few medical professionals are using PEEK implants. These implants have a wide range of unique qualities. 3D printing technologies are applicable for low volume production to fulfil the customised demand of surgeon/patient. ${ }^{3}$ 3D printing technology is known as additive manufacturing (AM). Mostly Fused Deposition Modelling (FDM) printers are preferred to print PEEK material. In this technology, the material used is in the form of a wire. ${ }^{4-6}$

3D printing technologies allow the construction of complex design geometry PEEK implants. However, it is challenging to manufacture them by traditional manufacturing technologies. ${ }^{7}$ 3D printing can manufacture lighter weight implants and reduce inventory as implants are made as per individual demands. It manufactures a 3D model by joining of material layer by layer, there by producing a unit 3D model with a lower cost without the requirement of any tooling. This technology is rapidly growing to fabricate patient-specific implants of bone,

\footnotetext{
* Corresponding author.

E-mail addresses: ahaleem@jmi.ac.in (A. Haleem), mjavaid@jmi.ac.in (M. Javaid).

https://scholar.google.co.in/citations? user =4047148AAAAJ\&hl=en (A. Haleem), https://scholar.google.co.in/citations? user = rfyiwvsAAAAJ\&hl=en (M. Javaid)
} 
prosthetic, heart and its components. ${ }^{8,9}$

In medical, the main aim is to maximise the power-to-weight ratio and create development and innovation by using the high-performance material. PEEK is a high-performance polymer which used for manufacturing of medical implants and devices which has a high capability of load bearing. Implants are bone-friendly and more compatible than metal implants. ${ }^{10-12}$ For the manufacturing of spinal cages, it has a significant role to solve various other problem of complicated surgery. Analysed a spinal rod manufactured by PEEK materials and found it to be beneficial than the conventional metal rod. ${ }^{13}$ It has a melting temperature at around $343^{\circ} \mathrm{C}$. It has excellent wear and abrasion resistance and less coefficient of friction. In medical, this material has various demanding applications. ${ }^{14,15}$

\section{What is polyether ether ketone (PEEK)}

PEEK is a top-notch organic thermoplastic polymer; it is colourless and can be used suitably for modelling accurate parts with good quality. It has broad application in medical, dentistry, aerospace, automotive and other associated areas. These materials are semi-crystalline thermoplastics having excellent mechanical properties. ${ }^{9,11}$ It shows excellent strength, dimensional stability and stiffness and sustains high temperature which replaces metal. Without the requirement of lubrication, it has high wear resistance and low coefficient of friction. Due to the robustness of this material, it is used to manufacturing demanding products such as medical implants, piston parts, bearing, pumps, electrical cable insulation and compressor plate valves. It is also applicable for ultra-high vacuum applications. This material is useable where there are requirements of continuous high temperature, and it has a melting temperature at $343^{\circ} \mathrm{C} .{ }^{16,17}$

\section{Properties of PEEK implants}

PEEK materials show excellent mechanical properties with Young's modulus of $3.6 \mathrm{GPa}$ and tensile strength between 90 and $100 \mathrm{MPa}$. Implants manufactured by PEEK have a unique combination of properties such as temperature resistance, excellent chemical wear and numerous processing capabilities. ${ }^{18-20}$ Table 1 , provides the various properties of PEEK that make it suitable for medical purposes.

\section{Research objective}

Medical applications required implants and parts which are manufactured through different technologies and are putting into the human body. Now a day, implants of metal like titanium oxide, cobalt steel and stainless steel are used, they have two significant issues of weight and customisation. The principal objective of this paper is to find out the research status of PEEK when it is being used in medical and 3D printing. The primary research objectives of this paper are:

I. To identify the research status on PEEK as used in medical and PEEK 3D printed parts used in medical.

II. Formalising a process to manufacture PEEK implants through additive manufacturing and comparing it with traditional manufacturing processes.

III. Identifying the primary advantages and disadvantages when a PEEK part is 3D printed and made through the traditional process.

IV. Identifying the major application areas of PEEK in medical

This research is to be conducted by review process to fulfil above research objectives.

\section{Basic requirements of the medical field as fulfilled by PEEK implants}

PEEK assists innovation, due to its required strength, durability and stiffness. It becomes popular due to its better elasticity as similar to human bone. ${ }^{1,21,22}$ Diverse requirements fulfilled by PEEK implants in the medical field are as under:

\section{$>$ Speedy recovery of patients}

PEEK manufactured implant help speedy recovery of the patient body after the surgery.

\section{$\triangleright$ Accuracy}

Implants manufactured by this material have better accuracy and fit precisely in the patient body.

$>$ Easily implemented during surgery

Table 1

Basic properties of PEEK implants.

\begin{tabular}{|c|c|c|}
\hline S. No & Property & Description \\
\hline 1 & Excellent biocompatibility & $\begin{array}{l}\text { - PEEK material is biocompatible } \\
\text { - It easily interacts with the human body and increases the success rate for medical applications such as replacement of } \\
\text { prosthesis, stents, and other medical implants } \\
\text { - Use of nano-material helps PEEK implants to perform required function concerning medical therapy that increase the } \\
\text { performance of patient during surgery } \\
\text { - These implants can implement in the patient body without causing deleterious changes }\end{array}$ \\
\hline 2 & Less weight & $\begin{array}{l}\text { - Implants manufactured by PEEK material have less weight as compared to other traditional material being used for } \\
\text { the same purpose } \\
\text { - These implants provide a natural look and feel with excellent safety and characteristics } \\
\text { - Lightweight PEEK implants enhance comfort, safety and quality of life of the patient }\end{array}$ \\
\hline 3 & Good mechanical properties & $\begin{array}{l}\text { - PEEK implants can withstand and not deform during a load of the whole body } \\
\text { - It provides constant function during the variation of the temperature of the body } \\
\text { - It has high rigidity, modulus stability and chemical resistance }\end{array}$ \\
\hline 4 & High tensile strength & $\begin{array}{l}\text { - These implants have high tensile strength under the action of the load } \\
\text { - Implants have maximum tensile strength can withstand before breaking which is beneficial for the human body } \\
\text { - Its tensile strength is } 90-100 \mathrm{MPa}\end{array}$ \\
\hline 5 & Low moisture absorption & $\begin{array}{l}\text { - This material has a low moisture absorption } \\
\text { - It needs less drying time which is suitable for a medical purpose }\end{array}$ \\
\hline 6 & High flexible & $\begin{array}{l}\text { - PEEK material is capable of bent easily without breaking } \\
\text { - Has better flexibility }\end{array}$ \\
\hline 7 & $\begin{array}{l}\text { Suitable for high vacuum or pressure } \\
\text { applications }\end{array}$ & $\begin{array}{l}\text { - Used in medical for the manufacturing of pressure or vacuum devices } \\
\text { - It increases the performance of devices that have highly resistant to most chemicals }\end{array}$ \\
\hline 8 & Stable high temperature & $\begin{array}{l}\text { - PEEK materials stable high temperature which is beneficial for medical and engineering applications } \\
\text { - It melts at } 343^{\circ} \mathrm{C} \text { which have a high melting temperature as compared to most of other thermoplastics } \\
\text { - It has good toughness, low toxicity and excellent abrasion resistance. }\end{array}$ \\
\hline
\end{tabular}


As implants are made as per individual specifications and are used easily for surgery.

\section{$>$ Flexible}

These materials are having higher flexibility such as manufacturing of cardiac valves for the patient suffering from heart diseases.

\section{$>$ Efficiency}

Implants can assist the load of the body that increases the efficiency of the patient.

$>$ Increase success rate of operation

During operation, these implants increase the success rate of operation due to its excellent material properties.

\section{Research status on PEEK in medical and PEEK 3D printing in medical}

\subsection{Research status on PEEK in medical}

Research on PEEK in medical is continuously increasing. Scopus database is searched through keywords "PEEK" "medical" and identified 426 articles from 1976 to November 2018. There was only one article in 1976. Then in 1979, two articles were published, and in the years 1981, 1985, 1986, 1987, 1988 and 1990 one article each year. In 1991, five articles published. In 1992, 1992, 1994 and1996, there was decrement of publication, in these years only one article was published. In 1997 (two), 1998 (four), 1999 (three), 2000 (two), 2001 (five), 2002 (five), 2003 (twelve), 2004 (five), 2005 (ten), 2006 (ten), 2007 (eighteen), 2008 (eighteen), 2009 (nineteen), 2010 (twenty one), 2011 (seventeen), 2012 (thirty one), 2013 (thirty), 2014 (thirty four), 2015 (forty five), 2016 (thirty three), 2017 (forty) and till November 2018, forty two articles are published so far. So, we observed a rapid increment of publications in the past ten years.

Different journals are publishing research articles on 'PEEK in medical', and out of these journals, the top journal is "Surface and coatings technology" that has published eight articles. "Materials Letters" and "Materials science and engineering C" published seven articles each. "Applied surface science", "International Journal of nanomedicine", "Nanomedicine", "Medical device and diagnostic industry" and "Spine" published five papers each. "Chinese Journal of tissue engineering research", "Chinese Journal of tissue engineering research", "Colloids and Surfaces biointerfaces", "Journal of applied polymer science", "Journal of materials science materials in medicine", "Key engineering materials", "Plasma processes and polymers", "Plastics technology", and "Wear" journal published four articles by each. Rest journals and sources also have a significant contribution in this field.

Materials Science field provides a maximum contribution of $27 \%$. Secondly, $21 \%$ contribution is from the medical field. Whereas 'Engineering' contributes 12\%, 'Physics and astronomy' 6\%, "Chemical Engineering" also contributes 6\%, "Chemical Engineering" again contributes 6\%, 'Business, Management and accounting' contributes 4\% and there is $12 \%$ contribution is given by "other fields" that includes Computer Science, Neuroscience, Pharmacology, Toxicology and Pharmaceutics, Dentistry, Psychology, Social sciences, Business, Management and accounting, Nursing, Arts and humanities, Earth and Planetary Sciences, Mathematics, Energy, Environmental science, Health professions, Agricultural and biological sciences, and Veterinary.

\subsection{Research status on PEEK $3 D$ printing in medical}

There are decidedly fewer research articles published in "PEEK 3D printing in medical". Searching with keywords as "PEEK" "medical" "3D printing" from Scopus; identified only ten articles. The first article in this area was published in 2014. In 2015, two articles were reported, and in 2016, three articles were published. In the year 2017, only one article published, and in 2018 to November, three articles are published so far.

Different journals published all these articles. Journals "Chinese journal of lung cancer", "Chinese Journal of tissue engineering research", "Composite structures", "Gaofenzi cailiao kexue yu gongcheng polymeric materials science and engineering", "Journal of materials science materials in medicine", "Journal of the mechanical behavior of biomedical materials", "Materials", "Materials and design", "Materials research innovations", "Virtual and physical prototyping" published one paper by each.

In area wise contribution of research, here we identified that "Engineering" and "Materials science" field have the equal contribution of $29 \%$ by each. Biochemistry, genetics and molecular biology contribute 13\%, Chemical engineering (9\%), Medicine (8\%) and "Computer science", "Mathematics", "Physics and astronomy" fields have the equal contribution of $4 \%$ by each.

From Scopus data, it has been analysed that research is reported on PEEK in medical, but there is less paper published in PEEK 3D printed in medical. In upcoming years, the PEEK material application may become commercially viable and acceptable in the medical field.

\section{Processes of making PEEK implants by the traditional manufacturing process and additive manufacturing process}

\subsection{Implants manufactured through the traditional manufacturing process}

In medical, manufacturing of personalised implant is the ultimate goal. In past years, only subtractive manufacturing methods like CNC and other traditional machines are used to manufacture PEEK implants. ${ }^{23,24}$ Fig. 1 shows the steps used to create PEEK implants by the traditional manufacturing process.

Fig. 1 shows the steps used to create PEEK implants using a

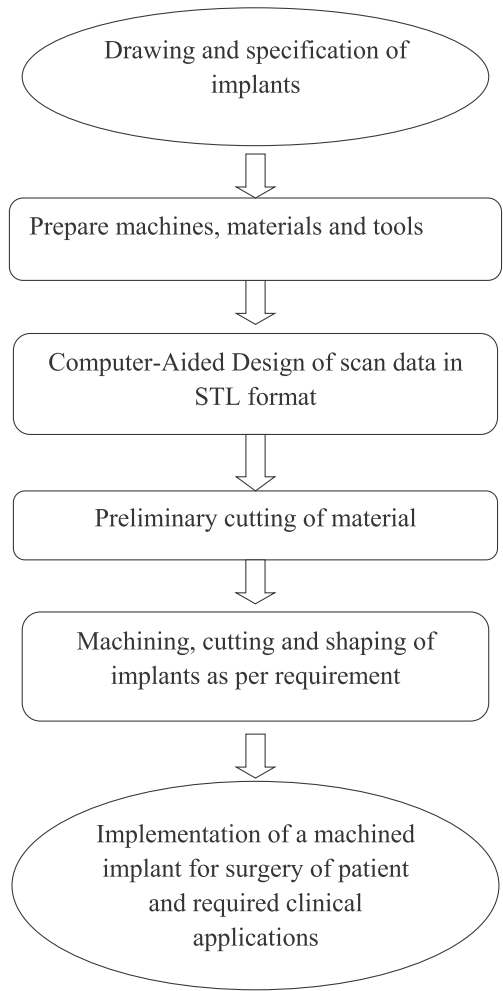

Fig. 1. Implants manufactured through the traditional manufacturing process. 


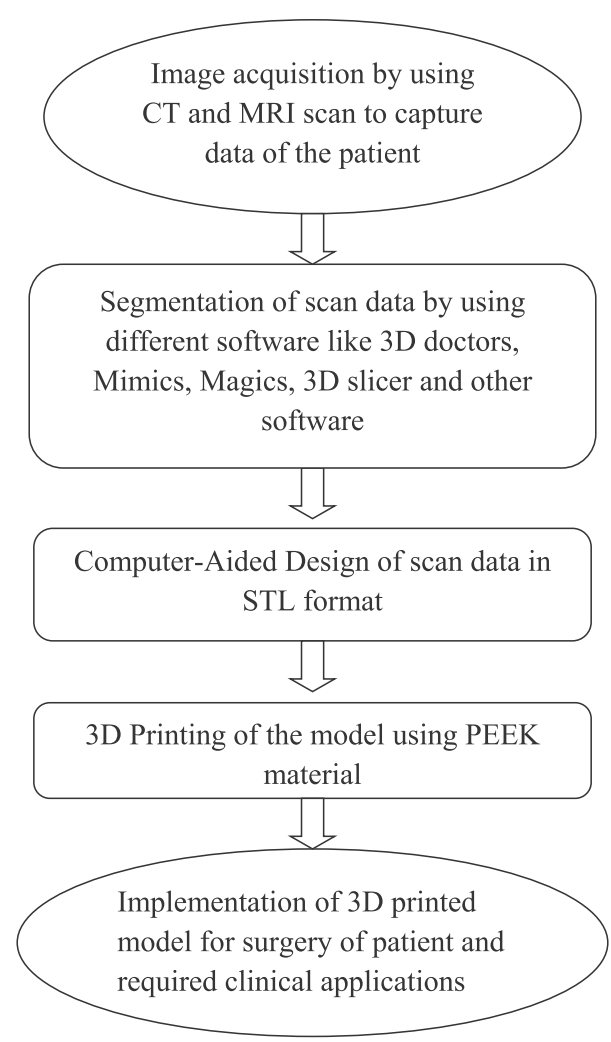

Fig. 2. Implants manufactured through the traditional manufacturing process.

traditional manufacturing process. Medical data is varying from patient to patient, so there is a requirement of customisation. This technique has some limitation such as time-consuming, material wastage, expensive and does not provide fit implants as per patient match. So there is a requirement of additive manufacturing that easily create customised implant as per patient match in less time.

\subsection{Implants manufactured through the additive manufacturing process}

Additive manufacturing technologies are now available to print patient-specific implants, devices, and instruments as per requirement. This technology easily fulfilled various challenges as compared to the traditional manufacturing method. Also, PEEK is used in 3D printing for manufacturing of complex design implants which is readily acceptable by the human body. ${ }^{25,26}$ PEEK is the highly useful material for medical to produce implants as compared to other materials. ${ }^{27,28}$ Now a day's doctors and surgeon are using $3 \mathrm{D}$ printing technologies for the production of PEEK implants as per required design. Fig. 2 shows the various step used to create implant through additive manufacturing.

PEEK 3D printed implants provide higher design freedom with a lesser waste of raw material. These implants reduce the failure rate of the patient and are bone-friendly. PEEK 3D printing technologies efficiently fulfil this customised requirement of the patient. Computer tomography (CT) and Magnetic resonance imaging (MRI) are used to obtained data of the individual patient and then converted into 3D CAD data by using different software in standard triangulate language (STL) format. This 3D CAD data is easily printable by 3D printing technologies. $^{29}$ These 3D printed PEEK implants are further tested and implemented for the surgery of a patient.

8. Fundamental advantages and disadvantages of 3D printing over traditional manufacturing method as for manufacturing of PEEK implants

3D printing technologies provide different steps to create medical implants with the help of CT and MRI scan. 3D printing technologies are readily applicable to the design and development of an implant that also creates good co-operation between patient and surgeon. ${ }^{30}$ The primary advantages of $3 \mathrm{D}$ printing over traditional manufacturing method for the manufacturing of PEEK implants are discussed in Table 2.

\section{Application areas of PEEK in the medical field}

In the healthcare industry, PEEK provides features such as biocompatibility, durability and excellent resistance. It is best and suitable material for pivotal applications such as orthopaedic implants, spinal implants, surgical equipment and dental equipment. ${ }^{47,48}$ PEEK implants devices are on rising in recent years due to its suitability of contact with the human body and is also incorporated into the manufacturing of active implantable devices. In the last few years, it is accepted widely in the human body over other traditional plastic and metals. Table 3 describes twelve crucial application areas of PEEK in medical.

In medical, there is a requirement of innovation to save the life of the patient. ${ }^{72,73}$ It is commonly used for the manufacturing of orthopaedic implants due to its modulus similar to bone. PEEK tubing is used for medical applications due to its high vacuum and pressure holding capability. This material is more useful than aluminium, steel, glass and other polymers. PEEK is a hard polymer, stiff and robust polymer having suitable wear properties. ${ }^{74}$ PEEK is also useful for repairing soft tissues and grafts.

\section{Discussion on findings}

PEEK materials are applicable for different surgical applications in the medical field. It can replace titanium and ceramic implants which are being used for different surgeries of orthopaedic, maxilla-facial, cranial and spine. These materials are tough having the capability to withstand high temperatures. It creates innovation for spinal arthroplasty devices. PEEK is used for reconstruction of the customised face of the individual patient with a required strength, durability and stiffness. Now, 3D printing is also available to manufacture implants with exact dimensioning as per patient requirements. It has more benefits over traditional manufacturing methods. 3D printing produces implants with higher accuracy that reduces the risk of surgery and maximises the success rate of operation. It converts innovative ideas of doctors and surgeon into reality. It is also applicable for cardiac surgery like manufacturing of heart valve prostheses, leaflet heart valves and stents. It is efficient for the cardio patient to provide comfort as it not provided by other materials. Another application of PEEK material in cardiology is the manufacturing of rotor of a micro axial pump. In dentistry, PEEK implants are used for tooth replacement. The application of PEEK is becoming popular due to its better elasticity as similar to natural bone.

\section{Future scope}

In future, PEEK may become suitable material to manufacture implantable medical devices having efficient output and can fulfil the innovative requirements. Due to its higher capability of patient comfort, it provides an essential improvement in medical and other associated fields. It creates a disruptive effect and increases the performance of surgery. Research on this material will increase. It will replace conventional material for fabricating medical implants. It will manufacture any biomedical splint, stents, and orthodontics devices as per patient requirement of strength. In the future, the applications of this material will create possibilities in the medical field. Doctors and surgeon adopt PEEK for the best treatment of the patient. It will create development in medical and become more common in other fields. This provides better surgery of patient and helps to create patient implants. In future, AM technology will help easy manufacture of customised/ 


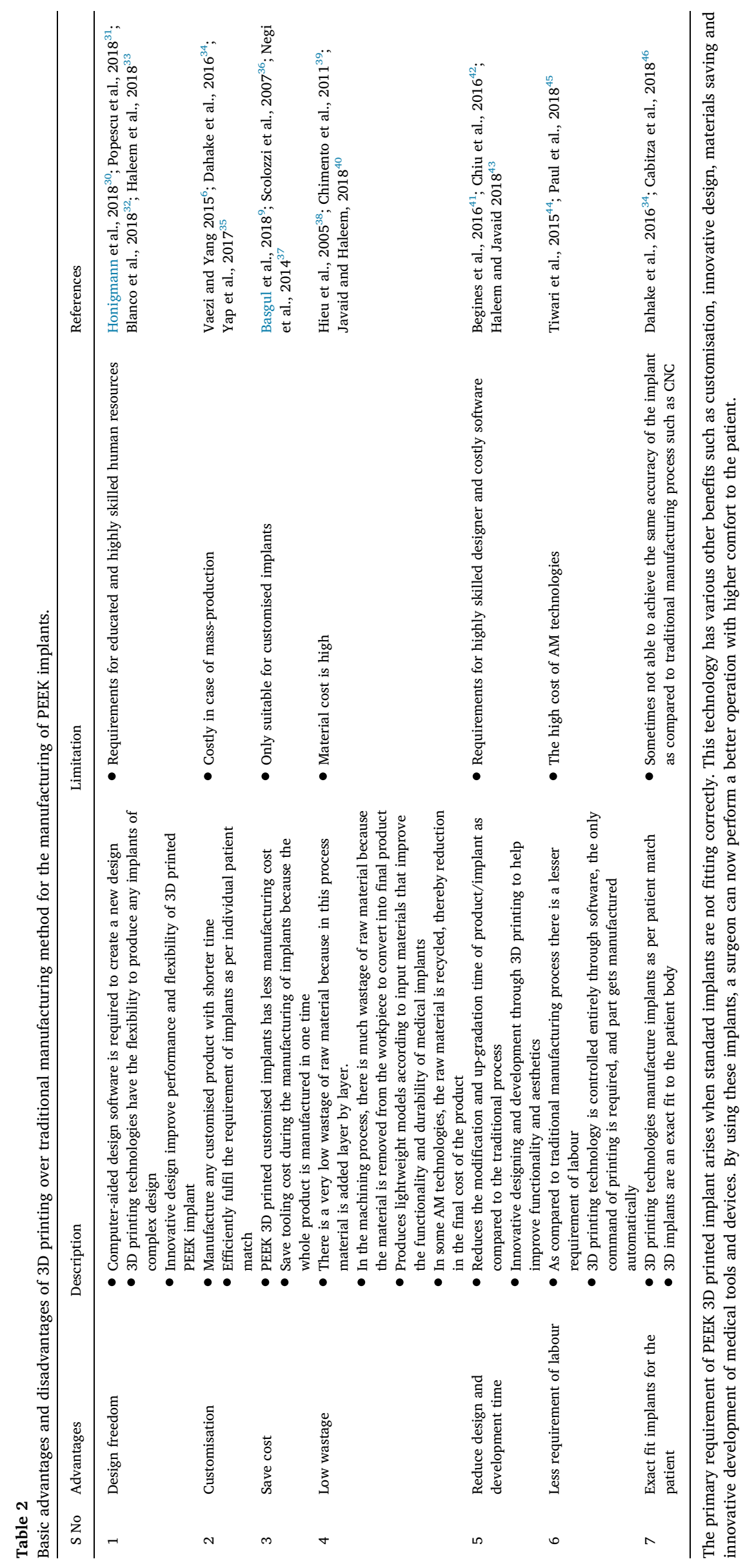


Table 3

Application areas of PEEK in the medical field.

\begin{tabular}{|c|c|c|c|}
\hline S No & Application areas & Description & References \\
\hline 1 & Orthopaedic surgery & $\begin{array}{l}\text { - Due to high strength, PEEK is used for various orthopaedic applications like hip } \\
\text { replacements, hip resurfacing and construction of femoral component } \\
\text { - Artificial implant of bone assist load of the body of the patient }\end{array}$ & $\begin{array}{l}\text { Steinberg et al., } 2013^{49} \text {; Faldini et al., } \\
2011^{50} \text {; Pace et al., } 2004^{51}\end{array}$ \\
\hline 2 & Medical tubing & $\begin{array}{l}\text { - } \text { It has is high purity, organic polymer with good resistance } \\
\text { - It is also having flexural modulus and requisite tensile strength } \\
\text { - PEEK tubing is used medical where high rigidity required }\end{array}$ & $\begin{array}{l}\text { Monich et al., } 2017^{52} \text {; Johansson et al., } \\
2014^{53}\end{array}$ \\
\hline 3 & Spinal implants & $\begin{array}{l}\text { - For spinal implants, PEEK offers many advantages as compared to metal. } \\
\text { - Include modulus close to bone which is the ultimate solution for the surgeon }\end{array}$ & $\begin{array}{l}\text { Kurtz and Devine, } 2007^{54} \text {; Barkamo et al., } \\
2013^{55}\end{array}$ \\
\hline 4 & Spinal fusion & $\begin{array}{l}\text { - Applications of this material are expanded significantly for the manufacturing of } \\
\text { intervertebral fusion cage } \\
\text { - It is a critical alternative of implants manufactured by metals }\end{array}$ & $\begin{array}{l}\text { Kulkarni et al., } 2007^{56} \text {; Wang et al., } 2010^{57} \text {; } \\
\text { Grupp et al., } 2014^{58}\end{array}$ \\
\hline 5 & Spinal arthroplasty devices & $\begin{array}{l}\text { - PEEK materials are used innovatively for spinal arthroplasty devices } \\
\text { - These are extremely hard and capability to withstand high temperatures }\end{array}$ & $\begin{array}{l}\text { Wang et al., } 1999^{59} \text {; Niu et al., } 2010^{60} \text {; Guo } \\
\text { et al., } 2018^{61}\end{array}$ \\
\hline 6 & Bone screws and pins & $\begin{array}{l}\text { - For the manufacturing of screws and pins, PEEK has excellent capability in required } \\
\text { strength used to hold the bone in place. } \\
\text { - Increase recovery chance of patient in less time }\end{array}$ & Li et al., $2015^{62}$; Fujihara et al., $2003^{63}$ \\
\hline 7 & $\begin{array}{l}\text { The smooth motion of the } \\
\text { spine }\end{array}$ & $\begin{array}{l}\text { - For developing a treatment in spine surgery, there is a requirement of smooth motion of } \\
\text { spine implant. } \\
\text { - PEEK are the key material that helps to enhance the movement of the spine }\end{array}$ & Guo et al., $2018^{61}$; Selim et al., $2018^{64}$ \\
\hline 8 & $\begin{array}{l}\text { Minimally invasive fusion } \\
\text { surgery }\end{array}$ & $\begin{array}{l}\text { - Used for innovation in spine surgery with minimally invasive fusion } \\
\text { - It also reduces nerve root retraction and tissue dissection }\end{array}$ & $\begin{array}{l}\text { Stratton-Powell et al., } 2016^{65} \text {; Selim et al., } \\
2018^{64}\end{array}$ \\
\hline 9 & Used for Stabilisation devices & $\begin{array}{l}\text { - PEEK materials are used for manufacturing of unique instrumentation for medical } \\
\text { - Used for soft-stabilisation and flexible-stabilisation for complex treatments }\end{array}$ & $\begin{array}{l}\text { Monich et al., } 2017^{52} \text {; Nieminen et al., } \\
2008^{66}\end{array}$ \\
\hline 10 & Face reconstruction & $\begin{array}{l}\text { - Applicable for the reconstruction of the face of the individual patient with high } \\
\text { strength, durability and stiffness } \\
\text { - These implants are easily workable, non-porous for facial reconstruction. }\end{array}$ & Scolozzi et al., $2007^{36}$; Kim et al., $2009^{67}$ \\
\hline 11 & Heart valve and stents & $\begin{array}{l}\text { - Used for the manufacturing of heart valves and stents having high durability } \\
\text { - Efficient for the cardio patient during surgery and performed high comfort as compared } \\
\text { to other materials }\end{array}$ & Zhou et al., $2011^{68}$; Guo et al., $2018^{61}$ \\
\hline 12 & Dental implants & $\begin{array}{l}\text { - In dentistry, PEEK also shows an excellent contribution to the manufacturing of missing } \\
\text { teeth to enhanced comfort of the patient. } \\
\text { - Used for construction of partial dentures, crowns and bridges due to its light weight and } \\
\text { strength }\end{array}$ & $\begin{array}{l}\text { Schwitalla et al., } 2015^{69} \text {; Sinha et al., } \\
2017^{70} \text {; Lee et al., } 2012^{71}\end{array}$ \\
\hline
\end{tabular}

designer PEEK implant. It provides close collaboration between the surgeon, doctors and patient. In future, it may also make development in the medical field such as tissue engineering. It provides cost-effective and innovative parts with requisite wear and mechanical strength. It improves the biocompatibility of load-bearing implants. 3D printing will be useful for manufacturing of different PEEK implants of head, neck, skull, jaw, face and other associated bones.

\section{Conclusion}

In the field of medical, fabrication of a customised implant is the primary goal. For patient-specific implants and devices, PEEK material seems a satisfactory material to fulfil the requirement of medical. It is colourless, and the models manufactured by them are suitable for various medical applications. 3D printing technologies easily fabricate complex shape PEEK implants by taking data of patient through CT/ MRI scan. It opens a new market which has various benefits like customisation, manufacture a replica of bones and other human parts with exact shape and size. These 3D manufactured PEEK implants improve patient satisfaction and safety. The surgeon can quickly tackle the medical problem of the patient. In the Orthopaedic field, it is applicable for manufacturing of load-bearing implants with similar properties as of human bone. PEEK is an advanced biomaterial which manufactures lesser weight implants to provide satisfaction to the patient with efficient performance. PEEK materials match with human body fluids. It has outstanding properties like biocompatibility, non-toxicity, osteoconductivity, and non-inflammatory nature. It is used for a wide variety of applications in bone tissue engineering, post teeth bleaching, spinal implants, Joint replacement and restoration of periodontal defects, therefore, helping improved patient outcomes with higher reliability. In upcoming years, PEEK materials to create a higher impact on various fields of engineering, medical, dentistry, and associated areas.

\section{Conflicts of interest}

None.

\section{Appendix A. Supplementary data}

Supplementary data to this article can be found online at https:// doi.org/10.1016/j.cegh.2019.01.003.

\section{References}

1. Panayotov IV, Orti V, Cuisinier F, Yachouh J. Polyetheretherketone (PEEK) for medical applications. J Mater Sci Mater Med. 2016;27:2-11.

2. Vogel D, Dempwolf H, Baumann A, Bader R. Characterization of thick titanium plasma spray coatings on PEEK materials used for medical implants and the influence on the mechanical properties. J Mech Behav Biomed Mater. 2018;77:600-608.

3. Javaid M, Haleem A. Current status and challenges of Additive manufacturing in orthopaedics: an overview. J Clin Orthopaed Trauma. 2018https://doi.org/10.1016/j. jcot.2018.05.008.

4. Honigmann P, Sharma N, Okolo B, Popp U, Msallem B, Thieringer FM. Patient-specific surgical implants made of 3D printed PEEK: material, technology, and scope of surgical application. BioMed Res Int. 2018. https://doi.org/10.1155/2018/4520636.

5. Yang C, Tian X, Li D, Cao Y, Zhao F, Shi C. Influence of thermal processing conditions in $3 \mathrm{D}$ printing on the crystallinity and mechanical properties of PEEK material. $J$ Mater Process Technol. 2017;248:1-7.

6. Vaezi M, Yang S. Extrusion-based additive manufacturing of PEEK for biomedical applications. Virtual Phys Prototyp. 2015;10:123-135.

7. Haleem A, Javaid M. Role of CT and MRI in the design and development of orthopaedic model using additive manufacturing. J Clin Orthopaed Trauma. 2018;9(3):213-217.

8. Brockett CL, Carbone S, Abdelgaied A, Fisher J, Jennings LM. Influence of contact pressure, cross-shear and counterface material on the wear of PEEK and CFR-PEEK for orthopaedic applications. J Mech Behav Biomed Mater. 2016;63:10-16.

9. Basgul C, Yu T, MacDonald DW, Siskey R, Marcolongo M, Kurtz SM. Structureproperty relationships for 3D-printed PEEK intervertebral lumbar cages produced using fused filament fabrication. J Mater Res. 2018;33(14):2040-2051.

10. Rae PJ, Brown EN, Orler EB. The mechanical properties of poly (ether-ether-ketone) (PEEK) with emphasis on the large compressive strain response. Polymer (Guildf). 2007; 48:598-615.

11. Godara A, Raabe D, Green S. The influence of sterilization processes on the 
micromechanical properties of carbon fiber-reinforced PEEK composites for bone implant applications. Acta Biomater. 2007;3:209-220.

12. Jalbert F, Boetto S, Nadon F, Lauwers F, Schmidt E, Lopez R. One-step primary reconstruction for complex craniofacial resection with PEEK custom-made implants. $J$ Cranio-Maxillo-Fac Surg. 2014;42:141-148.

13. Walter J, Kuhn SA, Reichart R, Kalff R, Ewald C. PEEK cages as a potential alternative in the treatment of cervical spondylodiscitis: a preliminary report on a patient series. Eur Spine J. 2010;19(6):1004-1009.

14. Han C, Lee E, Kim H, Koh Y, Kim KN. The electron beam deposition of titanium on polyetheretherketone (PEEK) and the resulting enhanced biological properties Biomaterials. 2010;31:3465-3470.

15. Wu X, Liu X, Wei J, Ma J, Deng F, Wei S. Nano-TiO2/PEEK bioactive composite as a bone substitute material: in vitro and in vivo studies. Int J Nanomed. 2012;7:1215-1225.

16. Sarot JR, Contar CM, Cruz AC, de Souza Magini R. Evaluation of the stress distribution in CFR-PEEK dental implants by the three-dimensional finite element method. J Mater Sci Mater Med. 2010;21:2079-2085.

17. Haleem A, Javaid M, Vaish A, Vaishya R. Three-dimensional-printed polyether ether ketone implants for orthopedics. Indian J Orthop. 2018. https://doi.org/10.4103/ ortho.IJOrtho 49918.

18. Santing HJ, Meijer HJA, Raghoebar GM, Özcan M. Fracture strength and failure mode of maxillary implant-supported provisional single crowns: a comparison of composite resin crown fabricated directly over PEEK abutments and solid titanium abutments. Clin Implant Dent Relat Res. 2012;14:882-889.

19. Wang HR, Li XL, Dong J, Yuan FL, Zhou J. Skip-level anterior cervical discectomy and fusion with self-locking stand-alone PEEK cages for the treatment of two noncontiguous levels of cervical spondylosis. J Spinal Disord Tech. 2013;26(7):286-292.

20. Dandy LO, Oliveux G, Wood J, Jenkins MJ, Leeke GA. Accelerated degradation of Polyetheretherketone (PEEK) composite materials for recycling applications. Polym Degrad Stabil. 2015;112:52-62.

21. Scholes SC, Unsworth A. Wear studies on the likely performance of CFR-PEEK/ CoCrMo for use as artificial joint bearing materials. J Mater Sci Mater Med. 2009;20(1):163-170.

22. Najeeb S, Zafar MS, Khurshid Z, Siddiqui F. Applications of polyetheretherketone (PEEK) in oral implantology and prosthodontics. J Prosthodont Res. 2016;60:12-19.

23. Rousseau MA, Lazennec JY, Saillant G. Circumferential arthrodesis using PEEK cages at the lumbar spine. J Spinal Disord Tech. 2007;20(4):278-281.

24. Nakahara I, Takao M, Bandoh S, Bertollo N, Walsk WR, Sugano N. In vivo implant fixation of carbon fiber-reinforced PEEK hip prostheses in an ovine model. $J$ Orthop Res. 2013;31(3):485-492.

25. Roskies M, Jordan JO, Fang D, et al. Improving PEEK bioactivity for craniofacial reconstruction using a 3D printed scaffold embedded with mesenchymal stem cells. $J$ Biomater Appl. 2016;31(1):132-139.

26. Zhao F, Li D, Jin Z. Preliminary investigation of poly-ether-ether-ketone based on fused deposition modeling for medical applications. Materials (Basel). 2018;11(2):E288. https://doi.org/10.3390/ma11020288.

27. Wu W, Geng P, Li G, Zhao D, Zhang H, Zhao J. Influence of layer thickness and raster angle on the mechanical properties of 3d-printed PEEK and a comparative mechanical study between PEEK and ABS. Materials. 2015;8(9):5834-5846.

28. Haleem A, Javaid M, Saxena A. Additive manufacturing applications in cardiology: a review. Egypt Heart J. 2018https://doi.org/10.1016/j.ehj.2018.09.008.

29. Gómez-Ciriza G, Hussain T, Gómez-Cía T, Valverde I. Potential of 3D-printed models in planning structural interventional procedures. Intervent Cardiol. 2015;7:1-5.

30. Javaid M, Haleem A. Additive manufacturing applications in medical cases: a literature-based review. Alexandria J Med. 2017https://doi.org/10.1016/j.ajme.2017 09.003.

31. Popescu D, Laptoiu D, Marinescu R, Botezatu I. Design and 3D printing customized guides for orthopaedic surgery - lessons learned. Rapid Prototyp J. 2018;24(5):901-913.

32. Blanco AM, Krauel L, Artés FF. Development of a patients-specific 3D-printed preoperative planning and training tool, with functionalized internal surfaces, for complex oncologic cases. Rapid Prototyp J. 2018https://doi.org/10.1108/RPJ-03 2018-0063.

33. Javaid M, Haleem A, Kumar L. Current status and applications of 3D scanning in dentistry. Clin Epidemiol Global Health. 2018. https://doi.org/10.1016/j.cegh.2018. 07.005 .

34. Dahake SW, Kuthe AKM, Mawale MB, Bagde AD. Applications of medical rapid prototyping assisted customized surgical guides in complex surgeries. Rapid Prototyp J. 2016;22:934-946.

35. Yap YL, Tan YSE, Tan HKJ, et al. 3D printed bio-models for medical applications. Rapid Prototyp J. 2017;23:227-235.

36. Scolozzi P, Martinez A, Jaques B. Complex orbito-fronto-temporal reconstruction using computer-designed PEEK implant. J Craniofac Surg. 2007;18:224-228.

37. Negi S, Dhiman S, Sharma RK. Basics and applications of rapid prototyping medical models. Rapid Prototyp J. 2014;20:256-267.

38. Hieu LC, Zlatov N, Sloten JV, et al. Medical rapid prototyping applications and methods. Assemb Autom. 2005;2:284-292

39. Chimento J, Highsmith MJ, Crane N. 3D printed tooling for thermoforming of medical devices. Rapid Prototyp J. 2011;17(5):387-392.

40. Javaid M, Haleem A. Additive manufacturing applications in orthopaedics: a review. J Clin Orthopaed Trauma. 2018;9(3):202-206.

41. Begines B, Hook AL, Alexander MR, Tuck CJ, Wildman RD. Development, printability and post-curing studies of formulations of materials resistant to microbial attachment for use in inkjet-based 3D printing. Rapid Prototyp J. 2016;22(5):835-841.

42. Chiu MC, Lin YH. Simulation-based method considering design for additive manufacturing and supply chain: an empirical study of lamp industry. Ind Manag Data Syst. 2016;116(2):322-348

43. Haleem A, Javaid M. 3D scanning applications in medical field: a literature-based review. Clin Epidemiol Global Health. 2018https://doi.org/10.1016/j.cegh.2018.05.
006.

44. Tiwari SK, Pande S, Agrawal S, Bobade SM. Selection of selective laser sintering materials for different applications. Rapid Prototyp J. 2015;21(6):630-648.

45. Paul SC, Zijl GPAGV, Tan MJ, Gibson I. A review of 3D concrete printing systems and materials properties: current status and future research prospects. Rapid Prototyp $J$. 2018;24(4):784-798.

46. Cabitza F, Locoro A, Ravarini A. 3D printing objects as knowledge artifacts for a doit-yourself approach in clinical practice: a questionnaire-based user study in the orthopaedics domain. Data Technol Appl. 2018;52(1):163-186.

47. Ferguson SJ, Visser JM, Polikeit A. The long-term mechanical integrity of non-reinforced PEEK-OPTIMA polymer for demanding spinal applications: experimental and finite-element analysis. Eur Spine J. 2006;15:149-156.

48. Rahmitasari F, Ishida Y, Kurahashi K, Matsuda T, Watanabe M, Ichikawa T. PEEK with reinforced materials and modifications for dental implant applications. Dent $J$. 2017;5(4):35. https://doi.org/10.3390/dj5040035.

49. Steinberg EL, Rath E, Shlaifer A, Chechik O, Maman E, Salai M. Carbon fiber reinforced PEEK Optima-a composite material biomechanical properties and wear/ debris characteristics of CFPEEK composites for orthopedic trauma implants. J Mech Behav Biomed Mater. 2013;17:221-228.

50. Faldini C, Chehrassan M, Miscione MT, et al. Single-level anterior cervical discectomy and interbody fusion using PEEK anatomical cervical cage and allograft bone. J Orthop Traumatol. 2011;12:201-205.

51. Pace N, Spurio S, Rizzato G. Clinical trial of a new CF-PEEK acetabular insert in hip arthroplasty. Hip Int. 2004;14:132-133.

52. Monich PR, Berti FV, Porto LM, et al. Physicochemical and biological assessment of PEEK composites embedding natural amorphous silica fibers for biomedical applications. Mater Sci Eng C Mater Biol Appl. 2017;79:354-362.

53. Johansson P, Jimbo R, Kjellin P, Currie F, Chrcanovic BR, Wennerberg A. Biomechanical evaluation and surface characterization of a nano-modified surface on PEEK implants: a study in the rabbit tibia. Int J Nanomed. 2014;9:3903-3911.

54. Kurtz SM, Devine JN. PEEK biomaterials in trauma, orthopedic, and spinal implants. Biomaterials. 2007;28:4845-4869.

55. Barkamo S, Wennerberg A, Hoffman M, et al. Nano-hydroxyapatite-coated PEEK implants: a pilot study in rabbit bone. J Biomed Mater Res. 2013;101:465-471.

56. Kulkarni AG, Hee HT, Wong HK. Solis cage (PEEK) for anterior cervical fusion: preliminary radiological results with emphasis on fusion and subsidence. Spine $J$. 2007;7(2):205-209.

57. Wang $\mathrm{H}$, Xu M, Zhang $\mathrm{W}$, et al. Mechanical and biological characteristics of diamondlike carbon coated poly aryl-ether-ether-ketone. Biomaterials. 2010;31:8181-8187.

58. Grupp T, Kabir K, Fritz B, Schwiesau J, Bloemer W, Jansson V. Evaluation of carbonfibre-reinforced PEEK as material for intervertebral disc replacement. Bone Joint Lett J. 2014;96 223-223.

59. Wang A, Lin R, Stark C, Dumbleton J. Suitability and limitations of carbon fiber reinforced PEEK composites as bearing surfaces for total joint replacements. Wear. 1999;225:724-727.

60. Niu CC, Liao JC, Chen WJ, Chen LH. Outcomes of interbody fusion cages used in 1 and 2-levels anterior cervical discectomy and fusion: titanium cages versus polyetheretherketone (PEEK) cages. J Spinal Disord Tech. 2010;23(5):310-316.

61. Guo Y, Chen S, Wang J, Lu B. Medical applications of polyether ether ketone. Transl Surg. 2018;3:12-16.

62. Li CS, Vannabouathong C, Sprague S, Bhandari M. The use of carbon-fibre-reinforced (CFR) PEEK material in orthopedic implants: a systematic review. Clin Med Insights Arthritis Musculoskelet Disord. 2015;8:33-45.

63. Fujihara K, Huang ZM, Ramakrishna S, Satknanantham K, Hamada H. Performance study of braided carbon/PEEK composite compression bone plates. Biomaterials. 2003;24:2661-2667.

64. Selim A, Mercer S, Tang F. Polyetheretherketone (PEEK) rods for lumbar fusion: a systematic review and meta-analysis. Internet J Spine Surg. 2018;12(2):190-200.

65. Stratton-Powell AA, Pasko KM, Brockett CL, Tipper JL. The biologic response to polyetheretherketone (PEEK) wear particles in total joint replacement: a systematic review. Clin Orthop Relat Res. 2016;474(11):2394-2404.

66. Nieminen T, Kallela I, Wuolijoki E, Kainulainen H, Hiidenheimo I, Rantala I. Amorphous and crystalline polyetheretherketone: mechanical properties and tissue reactions during a 3-year follow-up. J Biomed Mater Res. 2008;84:377-383.

67. Kim MM, Boahene KD, Byrne PJ. Use of customized polyetheretherketone (PEEK) implants in the reconstruction of complex maxillofacial defects. Arch Facial Plast Surg. 2009;11:53-57.

68. Zhou J, Xia Q, Dong J, et al. Comparison of stand-alone polyether ether ketone cages and iliac crest autografts for the treatment of cervical degenerative disc diseases. Acta Neurochir (Wien). 2011;153:115-122.

69. Schwitalla AD, Abou-Emara M, Spintig T, Lackmann J, Muller WD. Finite element analysis of the biomechanical effects of PEEK dental implants on the peri-implant bone. J Biomech. 2015;48:1-7.

70. Sinha N, Gupta N, Reddy KM, Shastry YM. Versatility of PEEK as a fixed partial denture framework. J Indian Prosthodont Soc. 2017;17(1):80-83.

71. Lee WT, Koak JY, Lim YJ, Kim SK, Kwon HB, Kim MJ. Stress shielding and fatigue limits of poly-ether-ether-ketone dental implants. J Biomed Mater Res B Appl Biomater. 2012;100:1044-1052.

72. Awasthi S, Pandey N. Rural background and low parental literacy associated with discharge against medical advice from a tertiary care government hospital in India. Clin Epidemiol Global Health. 2015;3:24-28.

73. Awasthi S, Verma T, Agarwal M, Singh JV, Srivastava NM, Nichterd M. Developing effective health communication messages for community-acquired pneumonia in children under five years of age: a rural North Indian qualitative study. Clin Epidemiol Global Health. 2017;5:107-116.

74. Gallagher EA, Lamorinière S, McGarry P. Multi-axial damage and failure of medical grade carbon fibre reinforced PEEK laminates: experimental testing and computational modelling. J Mech Behav Biomed Mater. 2018;82:154-167. 